\title{
Serotonin Mimics Tail Shock in Producing Transient Inhibition in the Siphon Withdrawal Reflex of Aplysia
}

\author{
Kent Fitzgerald and Thomas J. Carew \\ Departments of Psychology and Biology, Yale University, New Haven, Connecticut 06520
}

\begin{abstract}
Tail shock-induced modulation of the siphon withdrawal reflex of Aplysia has recently been shown to have a transient inhibitory component, as well as a facilitatory component. This transient behavioral inhibition is also seen in a reduced preparation in which a cellular reflection of the inhibitory process, tail shock-induced inhibition of complex EPSPs in siphon motor neurons, is observed. The biogenic amine serotonin (5-HT) is known to play a role in the facilitatory aspects of sensitization in Aplysia. The aim of this article was to examine whether 5-HT might also contribute to the inhibitory effects of tail shock in the siphon withdrawal reflex.

To examine this question, we carried out two kinds of experiments. First, in the isolated abdominal ganglion, we recorded intracellularly from siphon motor neurons and examined the effects of 5-HT on (1) complex (polysynaptic) EPSPs, produced by siphon nerve stimulation, and, simultaneously, (2) monosynaptic EPSPs from siphon sensory neurons. We found that, paralieling the effects of tail shock in the reduced preparation, 5-HT produced transient inhibition of the complex EPSP; the monosynaptic EPSP was facilitated by $5-\mathrm{HT}$. Second, we examined the behavioral effects of 5-HT on siphon withdrawal in a reduced preparation. We found that 5-HT again paralleled tail shock by producing transient inhibition of the siphon withdrawal reflex. Our results suggest that, in addition to its well-established facilitatory role in reflex modulation in Aplysia, 5-HT might play an important inhibitory role, as well.
\end{abstract}

The marine mollusk Aplysia californica has proven to be a valuable model system for exploring the neural mechanisms of learning and memory. Because the CNS of Aplysia is accessible to electrophysiological and biochemical analysis, considerable progress has been made in examining the cellular and molecular mechanisms of several forms of memory acquisition, storage, and retrieval (Carew and Sahley, 1986; Byrne, 1987; Hawkins et al., 1987). The most extensively studied form of learning in Aplysia is sensitization, the facilitation of a reflex response following a noxious or novel stimulus. For example, the defensive withdrawal reflex of the gill and siphon, elicited by a tactile

\footnotetext{
Received Aug. 24, 1990; revised Mar. 12, 1991; accepted Mar. 13, 1991.

We thank Diana Blazis, Emilie Marcus, Mark Stopfer, and William Wright for their helpful comments on the manuscript and Elizabeth McCance for excellent assistance in the behavioral experiments. This work was supported by a National Science Foundation graduate fellowship to K.F. and by National Science Foundation Grant BNS8311300 and Office of Naval Research Grant N00014-87-K0381 to T.J.C.

Correspondence should be addressed to Thomas J. Carew, Department of Psychology, Yale University, P.O. Box 11 A Yale Station, New Haven, CT 06520.

Copyright (C) 1991 Society for Neuroscience 0270-6474/91/112510-09\$03.00/0
}

stimulus to the siphon itself or to the surrounding mantle area, can be sensitized by electric shock to the tail (Carew et al., 1981; Marcus et al., 1988; Glanzman et al., 1989).

The neural circuit mediating the gill and siphon withdrawal reflex is relatively well understood, consisting in part of identified sensory neurons, interneurons, and motor neurons in the abdominal ganglion (Byrne et al., 1978; Hawkins et al., 1981a,b; Frost et al., 1988; for review, see Hawkins et al., 1987). Several converging lines of evidence implicate the biogenic amine serotonin $(5-\mathrm{HT})$ as one of the mediators of tail shock-induced facilitation in this reflex. It has long been known that 5-HT produces facilitation at the monosynaptic connection between siphon sensory neurons and siphon and gill motor neurons (Brunelli et al., 1976). Moreover, three more recent findings have provided additional evidence for the role of 5-HT in reflex facilitation. First, 5-HT applied directly to the abdominal ganglion facilitates the gill withdrawal reflex (Abrams et al., 1984). Second, serotonergic interneurons in the cerebral ganglion have becn identified that are activated by tail shock and facilitate synaptic transmission from sensory neurons onto motor neurons in the siphon withdrawal circuit (Mackey et al., 1989). Third, systemic depletion of 5-HT has been shown to interfere with behavioral refiex facilitation (Glanzman et al., 1989). Thus, there is compelling evidence that serotonergic facilitation of synapses in the siphon and gill withdrawal reflex circuits contributes significantly to behavioral reflex facilitation.

Recently, it has been shown that tail shock can have diverse behavioral effects in the siphon withdrawal reflex (KrontirisLitowitz et al., 1987; Mackey et al., 1987; Marcus et al., 1987, 1988). For example, Marcus et al. (1988) found that reflex responses were transiently inhibited by tail shock, and that sensitization emerged only after a significant delay of 20-30 min. These opposing effects of tail shock have been further dissociated within the neural circuit for siphon withdrawal. Paralleling the bchavioral results of Marcus et al. (1988), Wright et al. (1988, 1989,1991 ) found that the complex (polysynaptic) input to siphon motor neurons produced by stimulation of the siphon was transiently and significantly inhibited by tail shock, whereas the simultaneously recorded monosynaptic connection from sensory neurons to the same motor neurons was facilitated. Thus, tail shock can have different modulatory effects on the monosynaptic and polysynaptic components of the reflex.

Because tail shock produces multiple behavioral effects that can be reflected in changes in the complex EPSP in siphon motor neurons, and because serotonergic modulatory neurons are activated by tail shock, in the present study we investigated the possible role of 5-HT in producing some of the complex forms of modulation observed at behavioral and cellular levels. We 
found that 5-HT can mimic the inhibitory effects of tail shock. Specifically, 5-HT application produces significant transient inhibition of the complex synaptic input to siphon motor ncurons; simultaneously, 5-HT produces significant facilitation of the monosynaptic EPSP from siphon sensory neurons onto the same motor neurons. This inhibitory effect of 5-HT may be specific, because another transmitter implicated in sensitization, small cardioactive peptide $\mathrm{B}\left(\mathrm{SCP}_{\mathrm{B}}\right.$; Abrams et al., 1984), does not produce inhibition. Finally, consistent with the cellular results, 5-HT also produces significant transient inhibition of the siphon withdrawal reflex.

Some of the results described in this article have previously been presented in preliminary form (Fitzgerald and Carew, 1989; Fitzgerald et al., 1990).

\section{Materials and Methods}

Animals. Adult Aplysia californica (150-250 gm) were obtained from Marinus Inc. (Long Beach, CA) or Sea Life Supply (Sand City, CA). Animals were maintained in artificial seawater (Instant Ocean) on a 12hr: 12-hr light/dark cycle.

Cellular experiments. For cellular preparations, animals were first anesthetized by injection of approximately $100 \mathrm{ml}$ of isotonic $\mathrm{MgCl}_{2}$ solution. The abdominal ganglion, along with a length of the siphon nerve, was removed and immersed in $0.5 \%$ glutaraldehyde for $45 \mathrm{sec}$; this treatment minimizes contractions of the ganglionic sheath induced by 5-HT application. The ganglion was then pinned ventral side up in a 5-ml Petri dish, and the siphon nerve was attached to bipolar Ag$\mathrm{AgCl}$ electrodes to allow electrical stimulation of afferent fibers (Fig. 1). The sheath covering the ventral surface of the left side of the ganglion was removed to expose the LE cluster of siphon mechanoreceptor neurons and the LFS and LBS siphon motor neurons.

In each preparation, recordings were obtained from a sensory neuron and a motor neuron using 10-30-M glass microelectrodes filled with $3 \mathrm{~m} \mathrm{KCl}$. Intracellular amplifiers (Getting) were used for voltage amplification and current passing, and data were digitally recorded and analyzed on a microcomputer. LE sensory neurons were identified by their appearance, location, absence of synaptic input, and their electrical properties, including accommodation to sustained depolarization. The motor neuron was hyperpolarized to a level $40 \mathrm{mV}$ below resting potential to prevent firing of action potentials. Two types of EPSP were measured in the motor neuron: (1) the monosynaptic EPSP resulting from a single sensory neuron action potential (elicited by brief depolarization of the sensory neuron) and (2) the complex EPSP produced by electrical stimulation of the siphon nerve. The nerve stimulus was a single $0.5-1.0-\mathrm{msec}$ shock. Stimulus voltage (typically 5-10 V) was adjusted to produce a subthreshold (complex) EPSP in the motor cell comparable in amplitude to the EPSP caused by water jet stimulation of the siphon (approximately $40 \mathrm{mV}$; see Wright et al., 1991). The siphon nerve stimulus required to produce a complex EPSP of this amplitude was generally subthreshold for activation of the sensory neuron. In a few preparations, it was not possible to record the monosynaptic EPSP, and data were obtained only for the complex EPSP.

Throughout the experiment, the preparation was perfused with buffered saline solution consisting of (in $\mathrm{mM}$ ) $\mathrm{NaCl}, 460 ; \mathrm{MgCl}_{2}, 55 ; \mathrm{CaCl}_{2}$, $11 ; \mathrm{KCl}, 10$; Trizma (pH 7.6; Sigma), 10; the flow rate was approximately $10 \mathrm{ml} / \mathrm{min}$. 5-HT (5-hydroxytryptamine creatinine sulfate; Sigma) or synthetic Aplysia small cardioactive peptide $\mathrm{B}\left(\mathrm{SCP}_{\mathrm{B}}\right.$; Peninsula Laboratories) was bath applied by one of two methods: (1) perfusing the recording chamber for $2 \mathrm{~min}$ with saline solution containing the drug at the appropriate concentration $\left(5-\mathrm{HT}, 50\right.$ or $100 \mu \mathrm{M} ; \mathrm{SCP}_{\mathrm{B}}, 10$ $\mu \mathrm{M})$, or (2) ejecting a small volume ( $2 \mathrm{ml})$ of drug solution from a pipette positioned directly over the desheathed surface of the ganglion (pipette concentration of 5-HT or $\mathrm{SCP}_{\mathrm{B}}, 250 \mu \mathrm{M}$ ).

Behavioral experiments. Animals were anesthetized as described above, and the mantle organs (siphon, gill, and mantle shelf) were dissected, leaving them attached to the abdominal ganglion by the siphon nerve (see Fig. 7). The preparation was pinned in a $100-\mathrm{ml}$ dish, and the ganglion was desheathed as in the cellular experiments. Saline solution was injected into the base of the siphon to flush out $\mathrm{MgCl}_{2}$, and the dish was perfused with saline solution. The stimulus used to elicit siphon withdrawal was the same as that used for behavioral experiments in the

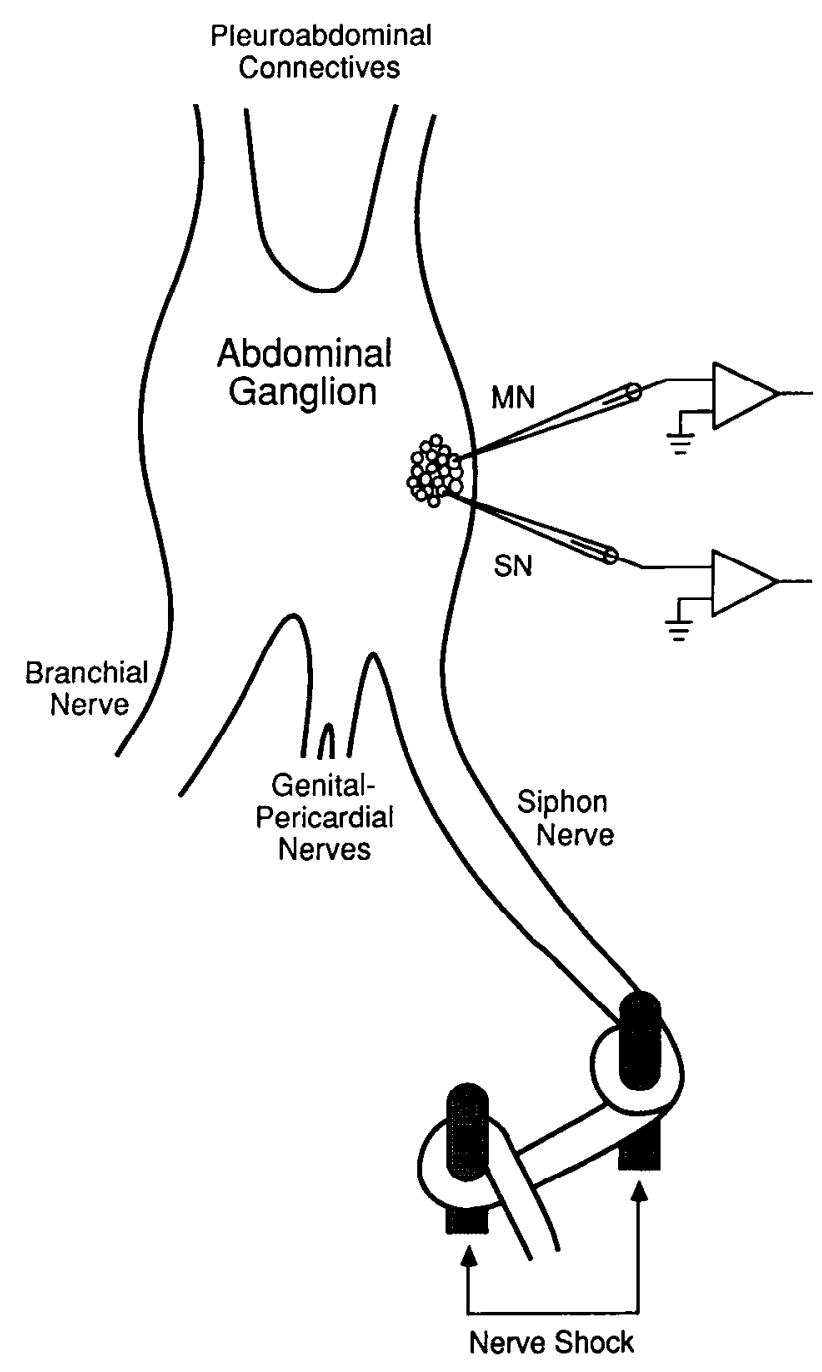

Figure 1. Isolated ganglion preparation used for cellular experiments. The abdominal ganglion was desheathed on the ventral surface, and intracellular microelectrode recordings were made from a siphon sensory neuron $(S N)$ and motor neuron $(M N)$. The siphon nerve was attached to posts to permit electrical stimulation.

accompanying paper (Wright et al., 1991): a water jet produced by a Picospritzer (General Valve) set at $25 \mathrm{psi}$ and $70-\mathrm{msec}$ duration was delivered with a pipette $(5-\mathrm{mm}$ inside diameter) positioned approximately $5 \mathrm{~mm}$ from the siphon. The duration of the resulting siphon contraction was timed by an observer who was blind to the experimental conditions. 5-HT $(50 \mu \mathrm{M})$ or saline solution (for control preparations) was applied for $30 \mathrm{sec}$ via a micropipette positioned close to the ganglion. Bath perfusion was interrupted only during drug application; thus, washout began at the termination of drug application.

Statistical analysis. In cellular experiments, statistical comparisons were made for both complex and monosynaptic EPSP amplitudes at two time points: test 1 ( $30 \mathrm{sec}$ following drug application) and test 2 (10 min after test 1). To test for initial effects of drug application, EPSP amplitudes at test 1 were computed as difference scores (test 1 minus the average of the two pretests for each preparation). To test for recovery, EPSP amplitudes at test 2 were computed as difference scores (test 2 minus test 1 for each preparation). Within group differences were analyzed using $t$ tests for repeated measures. In the behavioral experiment, siphon withdrawal durations for each animal were converted to percentages of the average of the animal's two pretests. Difference scores were computed for test 1 and test 2 , as above, and analyzed with $t$ tests. Parametric statistics were used to analyze both cellular and behavioral results because the data in each case were normally distributed. All $p$ values are reported as two-tailed, and all data are expressed in terms of means \pm standard errors of the mean. 

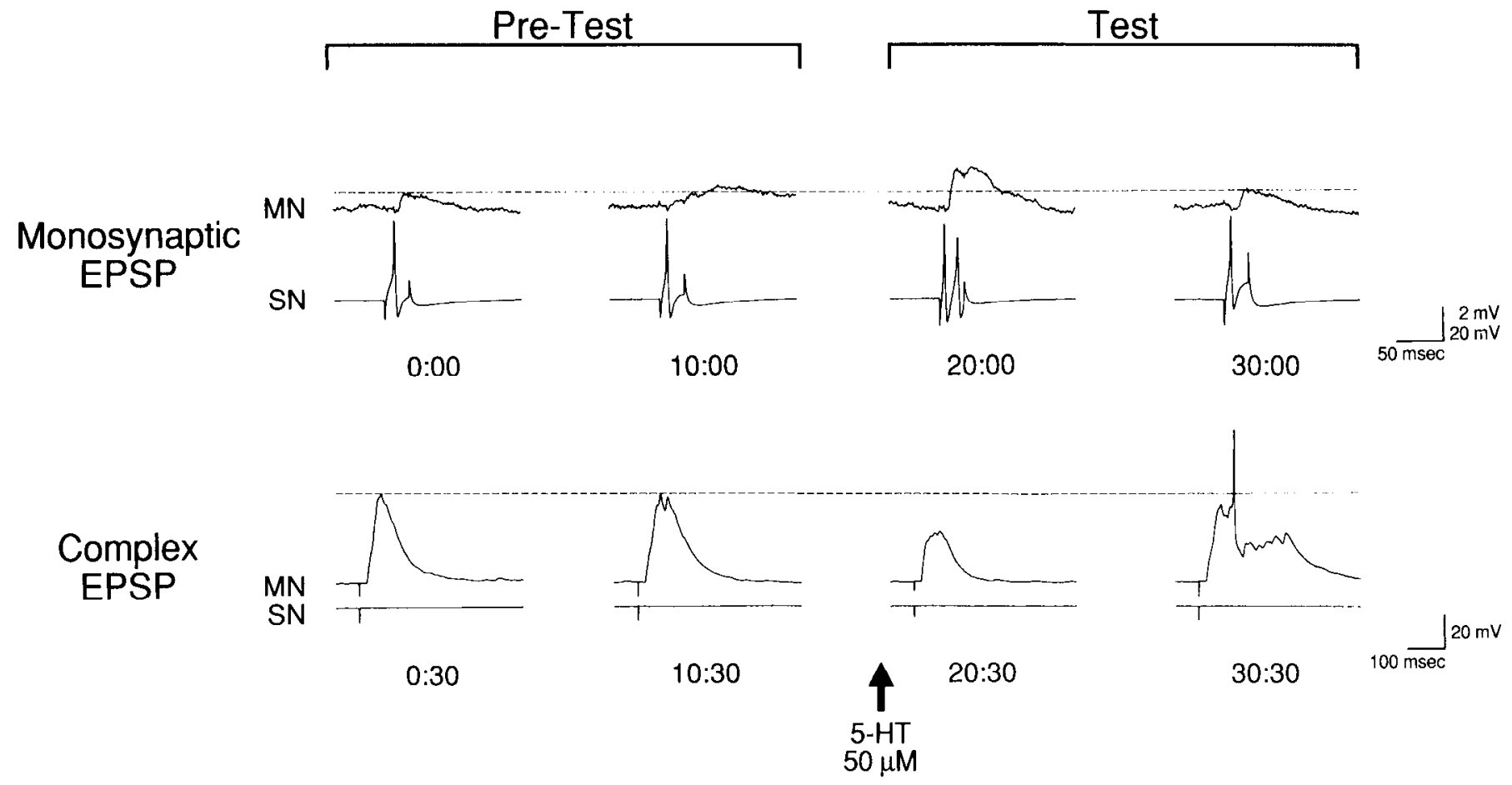

Figure 2. Effects of 5-HT on monosynaptic and complex EPSPs in siphon motor neurons: intracellular recordings from a siphon motor neuron $(M N)$ and sensory neuron $(S N)$. The monosynaptic EPSP $(t o p)$ and complex EPSP (bottom) were tested at 10-min intervals. Following two pretests, 5-HT $(50 \mu \mathrm{M})$ was bath applied (arrow). After 5-HT application, the monosynaptic EPSP was facilitated, while the complex EPSP was inhibited below baseline. Antiaccommodation is also apparent in the sensory neuron: the depolarizing current injection that elicited one action potential in the pretests produces two action potentials in the test after 5-HT. The broken lines indicate initial baseline.

\section{Results}

5-HT mimics the effects of tail shock by simultaneously producing inhibition of the complex EPSP and

facilitation of the monosynaptic EPSP

Wright et al. $(1988,1989,1991)$ showed that, $90 \mathrm{sec}$ after tail shock, complex EPSPs in siphon motor neurons were significantly inhibited, while the monosynaptic connection from siphon sensory neurons to the same motor neurons was simultaneously facilitated. We examined whether $5-\mathrm{HT}$ could mimic these diverse effects of tail shock.

Using the preparation shown in Figure 1, in the first experiment we examined the effects of $50 \mu \mathrm{M} 5-\mathrm{HT}$ on (1) the monosynaptic connection from a siphon sensory neuron to a siphon motor neuron, and (2) the complex EPSP elicited in the same motor neuron by electrical stimulation of the siphon nerve. Throughout the experiment, the monosynaptic and complex EPSPs were tested at $10-\mathrm{min}$ intervals. This test interval is the same that has been used in previous behavioral and cellular experiments; it produces minimal depression of the reflex response (Marcus et al., 1988) and of the complex EPSP (Wright et al., 1988, 1991). At least two pretests were given in each preparation. Seven and a half minutes after the last pretest, 5-HT was added to the perfusion medium for $2 \mathrm{~min}$. The first test occurred $30 \mathrm{sec}$ after the end of 5-HT application.

An example of our results is shown in Figure 2. Between the two pretcsts, the monosynaptic EPSP cxhibitcd considerablc depression. Such depression of the monosynaptic EPSP was commonly observed ( 29 out of 43 preparations). In contrast, between the two pretests, the complex EPSP was relatively stable. In the first test after 5-HT application, the monosynaptic
EPSP was clearly facilitated. However, at the same time, the complex EPSP in the motor neuron was inhibited well below baseline. In the next test, 10 min later, the monosynaptic EPSP had returned to its initial level, and the complex EPSP had recovered substantially from inhibition.

The mean amplitudes of complex and monosynaptic EPSPs from 15 preparations are shown in Figure 3. During the two pretests, the complex EPSP was quite stable $(N=15$; pretest 1 , $\bar{x}=43.7 \pm 2.44 \mathrm{mV}$; pretest $2, \bar{x}=44.4 \pm 2.93 \mathrm{mV}$ ). The average of these two pretests $(\bar{x}=44.0 \pm 2.62 \mathrm{mV})$ was used as the bascline for statistical comparisons (see Materials and Methods). The monosynaptic EPSP showed depression between the pretests, even at an interstimulus interval of $10 \mathrm{~min}(N=$ 11 ; pretest $1, \bar{x}=7.83 \pm 1.81 \mathrm{mV}$; pretest $2, \bar{x}=5.44 \pm 1.14$ $\mathrm{mV}$; average pretest, $\bar{x}=6.64 \pm 1.44 \mathrm{mV}$ ). Thirty seconds after application of 5-HT, in test 1, the complex EPSP was significantly inhibited (test 1 minus average pretest: $\bar{x}=-14.7 \pm$ $2.90 \mathrm{mV} ; t_{14}=-5.08 ; p<0.0001$ ). In contrast, the monosynaptic EPSP was significantly facilitated (test 1 minus average pretest: $\left.\bar{x}=3.63 \pm 1.49 \mathrm{mV} ; t_{10}=2.43 ; p<0.04\right)$. The amount of facilitation observed was comparable to previously published reports (e.g., Brunelli et al., 1976). Ten minutes later, in test 2 , the complex EPSP had recovered significantly (test 2 minus test $1: \bar{x}=8.86 \pm 1.75 \mathrm{mV} ; t_{13}=5.07 ; p<0.0001$ ), and the monosynaptic EPSP no longer showed facilitation. Thus, paralleling cellular experiments using tail shock (Wright et al., 1989, 1991), 5-HT causes transient inhibition of complex synaptic input from the siphon nerve, while at the same time it causes facilitation of the synapse from LE siphon sensory neurons onto siphon motor neurons.

To examine the effects of 5-HT more thoroughly, we next 


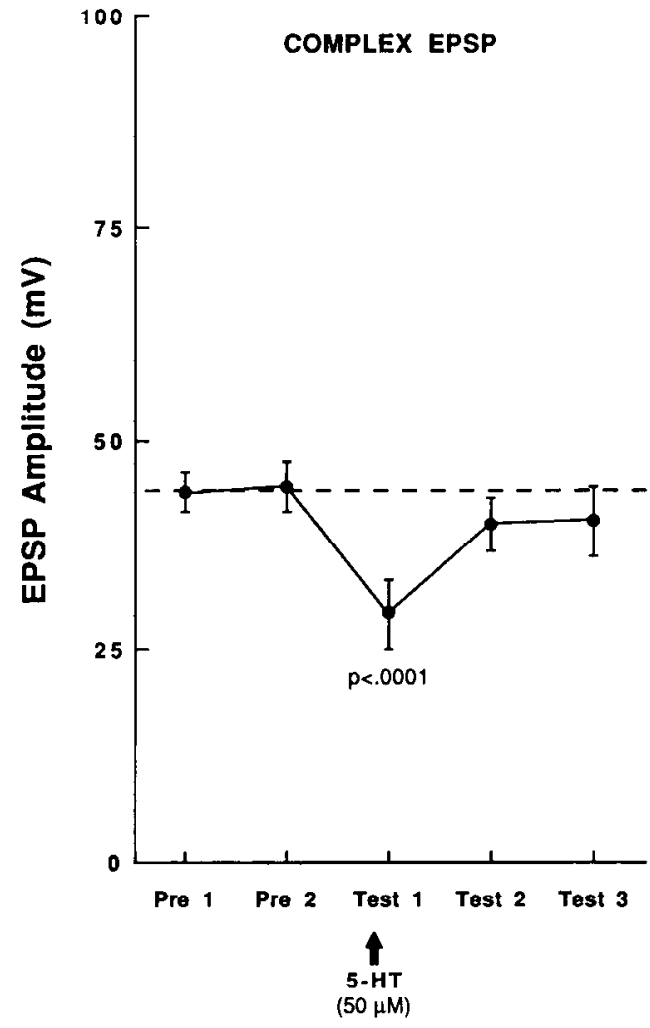

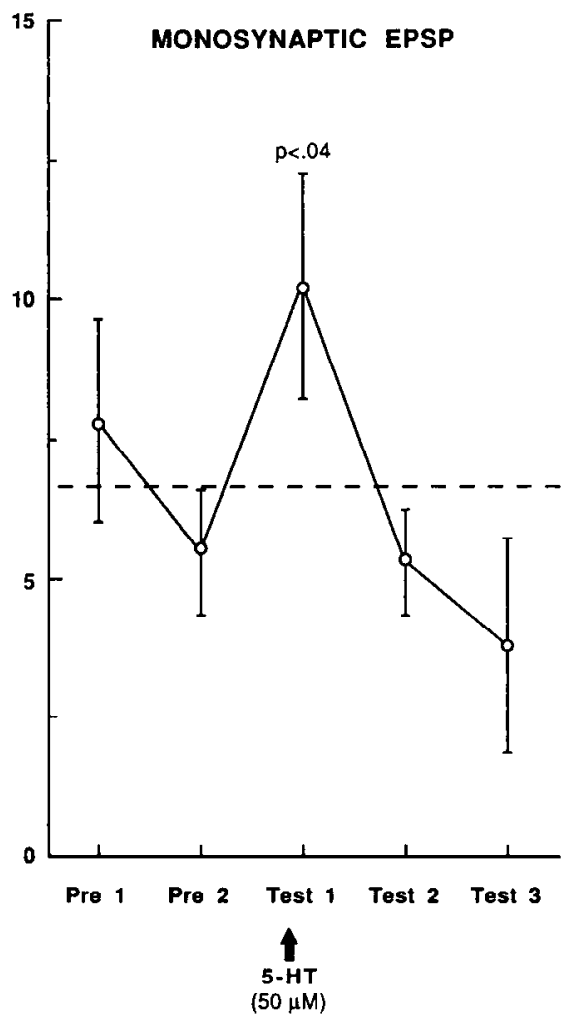

Figure 3. Summary of effects of 5-HT on complex and monosynaptic EPSPs. Mean EPSP amplitudes ( \pm SEM) at each test are given for the complex EPSP (left) and the monosynaptic EPSP (right; note difference in scale). Test times: for the monosynaptic EPSP, Pre $l=0 \mathrm{~min}$, Pre $2=10 \mathrm{~min}$, Test $1=20 \mathrm{~min}$, Test $3=30 \mathrm{~min}$; for the complex EPSP, Pre $I=0.5 \mathrm{~min}$, Pre $2=10.5 \mathrm{~min}$, Test $I$ $=20.5 \mathrm{~min}$, Test $3=30.5 \mathrm{~min}$. Error bars indicate SEM. The broken lines indicate the mean of the two pretests, which was used as the baseline for statistical comparisons. The complex EPSP $(N=15)$ is significantly inhibited at the first test after 5-HT, while the monosynaptic $\operatorname{EPSP}(N=11)$ is significantly facilitated. examined the effects of a range of concentrations, using the same experimental protocol as described above. The results are shown in Figure 4. Concentrations of 50, 100, or $250 \mu \mathrm{M} 5$-HT each produced significant inhibition of the complex EPSP $(50 \mu \mathrm{M}, N$ $=15$, test 1 minus average pretest: $\bar{x}=-14.7 \pm 2.90 \mathrm{mV} ; t_{14}$ $=-5.08 ; p<0.0001 ; 100 \mu \mathrm{M}, N=6$, test 1 minus average pretest: $\bar{x}=-16.7 \pm 6.09 \mathrm{mV} ; t_{5}=-2.74 ; p<0.05 ; 250 \mu \mathrm{M}$, $N=8$, test 1 minus average pretest: $\bar{x}=-21.8 \pm 6.28 \mathrm{mV} ; t_{7}$ $=-3.47 ; p<0.02$ ). There was a tendency toward greater inhibition at higher concentrations, but this trend was not statistically significant. Significant facilitation of the monosynaptic EPSP was observed only with $50 \mu \mathrm{M}$ 5-HT.

\section{$S C P_{B}$ does not produce inhibition of the complex EPSP}

A specific class of neuromodulators, the endogenous SCPs, has physiological and biochemical effects on the monosynaptic EPSP very similar to those of 5-HT (Abrams et al., 1984). In order to determine whether the transient inhibition observed with 5-HT was a general property of this class of neuromodulators, we examined the effects of $\mathrm{SCP}_{\mathrm{B}}$ on both monosynaptic and complex EPSPs. An example of our results is shown in Figure 5. Following application of $250 \mu \mathrm{M} \mathrm{SCP}$, both the complex and the monosynaptic EPSPs increased slightly above average pretest levels. Mean EPSP amplitudes from 18 preparations are shown in Figure 6. We found that, in contrast to 5-HT, SCP (at concentrations of 10 and $250 \mu \mathrm{M}$, which bracket those used for 5-HT) did not inhibit the complex EPSP, but rather caused a modest increase $(10 \mu \mathrm{M}, N=10$, test 1 minus average pretest: $\bar{x}=2.11 \pm 1.31 \mathrm{mV} ; 250 \mu \mathrm{M}, N=8$, test 1 minus average pretest: $\bar{x}=1.80 \pm 0.98 \mathrm{mV}$ ). At both concentrations, the increase in complex EPSP amplitude was not statistically significant. Thus, the inhibitory action of 5-HT on complex synaptic input is not observed with $\mathrm{SCP}_{\mathrm{B}}$.

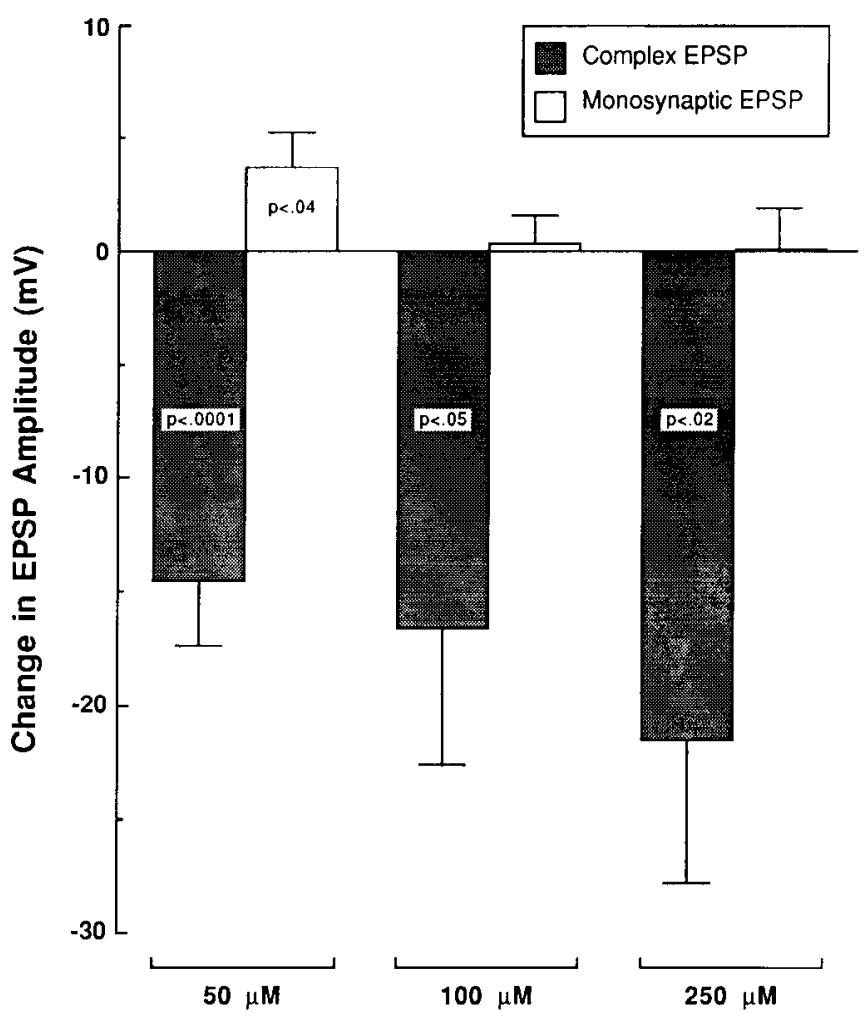

Figure 4. Effects of different concentrations of 5-HT. Summary of experiments using different concentrations of 5-HT $(50,100$, and 250 $\mu \mathrm{M})$. Data are expressed as difference scores, showing the change in EPSP amplitude at the first test after 5-HT, compared to the mean of the two pretests. Error bars indicate SEM. The complex EPSP (shaded bars) is significantly inhibited at all three concentrations. The monosynaptic EPSP (open bars) is significantly facilitated by $50 \mu \mathrm{M} 5-\mathrm{HT}$, but not by higher concentrations. 
Pre-Test

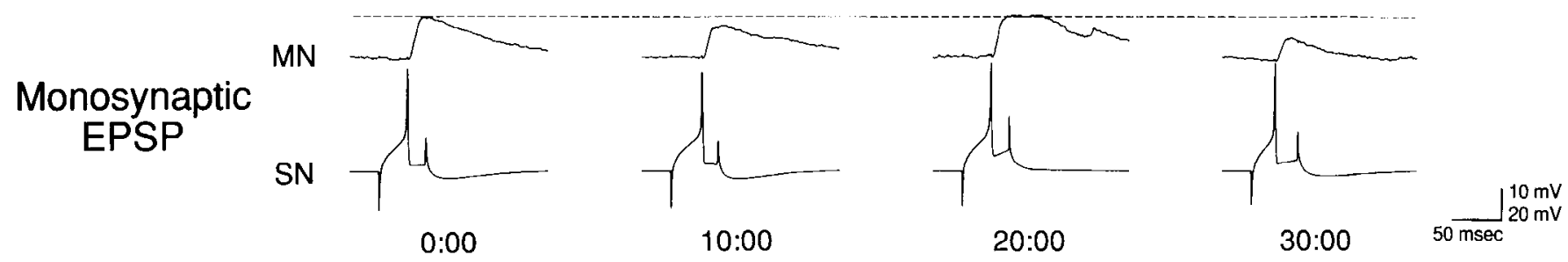

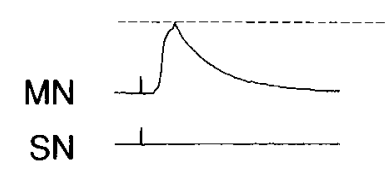

$0: 30$

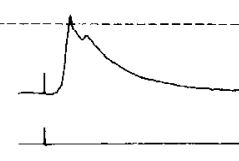

$10: 30$

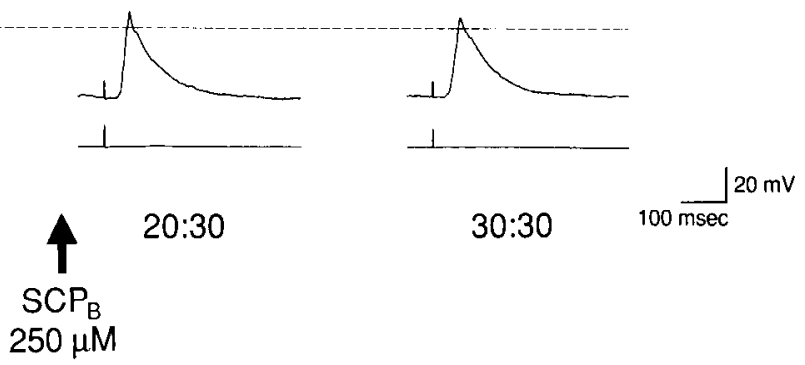

Figure 5. Effects of $\mathrm{SCP}_{\mathrm{B}}$ on monosynaptic and complex EPSPs in siphon motor neurons: intracellular recordings from a siphon motor neuron $(M N)$ and sensory neuron $(S N)$, as in Figure 2 . After $\mathrm{SCP}_{\mathrm{B}}$ application (arrow), both the monosynaptic and the complex EPSPs were very slightly increased.

\section{5-HT mimics the effects of tail shock by producing reflex inhibition}

Facilitation of the monosynaptic EPSP by 5 -HT has been observed often, and the mechanisms of this effect are well understood at biophysical and molecular levels (Byrne, 1987; Hawkins et al., 1987). However, the inhibition of the complex EPSP by 5 -HT that we observed has not been previously described. This surprising finding raised the important question of whether 5-HT could produce comparable inhibition of the behavioral reflex response. We examined this question using a surgically reduced preparation consisting of the mantle organs (siphon, gill, and mantle shelf), attached to the abdominal ganglion by the siphon nerve (Fig. 7). This preparation exhibited a reliable siphon withdrawal reflex in response to water jet stimulation and allowed application of 5-HT to the CNS, comparable to its administration in the cellular experiments described above. Preparations were randomly assigned to experimental or control groups ( $N=10$ per group), and siphon withdrawal was measured using a blind procedure (see Materials and Methods). Average baseline siphon withdrawal durations in the two pretests (presented at a 10-min interval as in the cellular experiments) were comparable for the two groups (experimental, $6.05 \pm 0.24 \mathrm{sec}$; control, $5.39 \pm 0.24 \mathrm{sec} ; t_{18}=1.93$, NS). To normalize the data,
Figure 6. Summary of effects of $\mathrm{SCP}_{\mathrm{B}}$ : mean EPSP amplitude ( \pm SEM) for the average pretest (solid bars) and the first test after $\mathrm{SCP}_{\mathrm{B}}$ application (open bars). Unlike 5-HT, $\mathrm{SCP}_{\mathrm{B}}$ at either $10 \mu \mathrm{M}(N$ $=10)$ or $250 \mu \mathrm{M}(N=8)$ does not produce inhibition of the complex EPSP, but causes slight increases (not statistically significant) in both the complex and monosynaptic EPSPs.
$10 \mu \mathrm{M}$ SCP $_{\text {B }}$

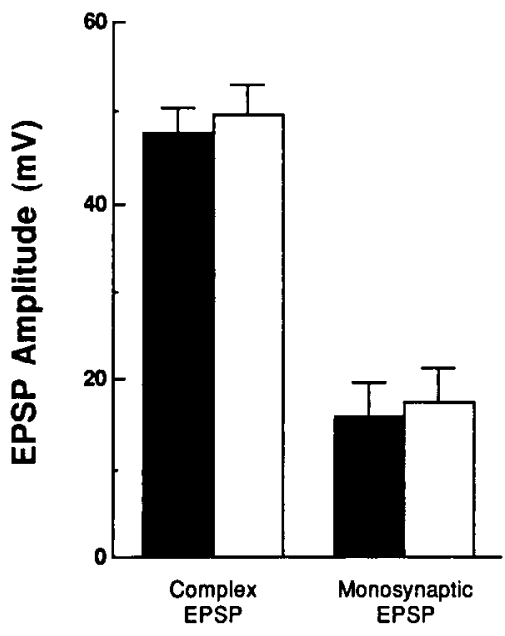

$250 \mu \mathrm{M} \mathrm{SCP}_{\mathrm{B}}$
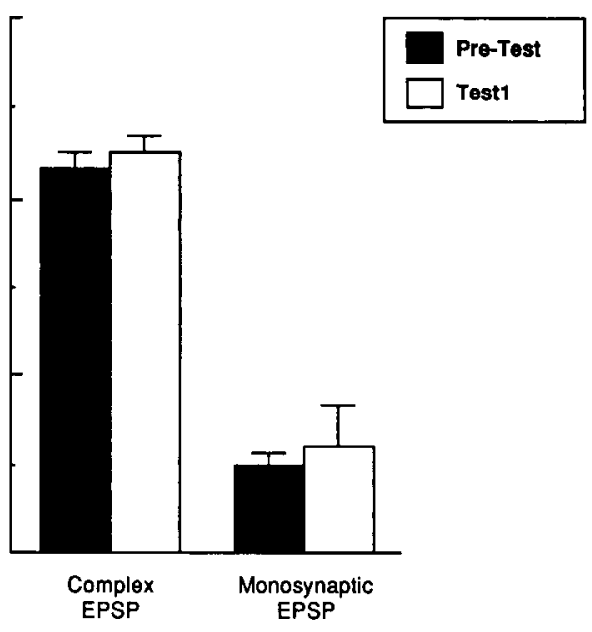


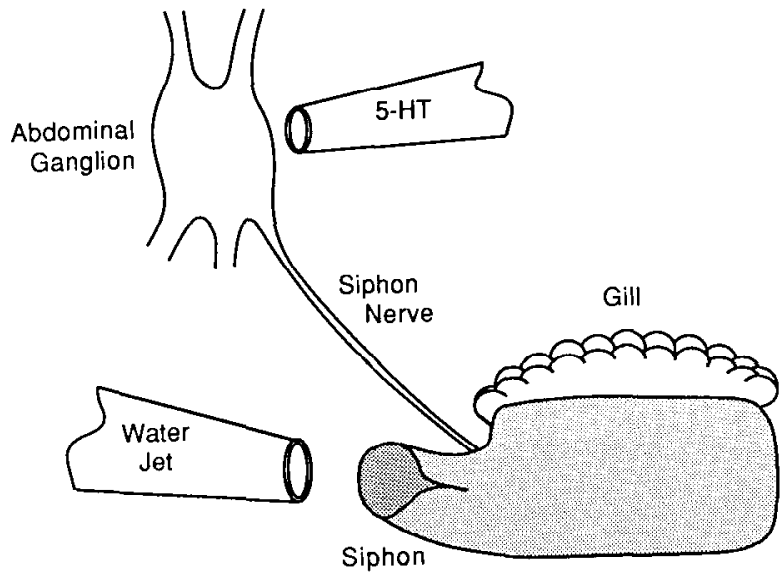

Figure 7. Reduced preparation used for behavioral experiments. The preparation consists of the siphon, gill, and mantle shelf, attached to the abdominal ganglion via the siphon nerve. The water jet, used to elicit siphon withdrawal, and the micropipette through which 5-HT was delivered, are shown.

the duration of each animal's siphon withdrawal was computed as a percentage of its own average pretest response. The results are shown in Figure 8. A within-group comparison revealed that application of 5-HT $(50 \mu \mathrm{M})$ to the CNS of experimental preparations caused significant inhibition of the duration of siphon withdrawal $\left(\bar{x}=79.8 \pm 4.19 \%\right.$ of pretest; $\left.t_{9}=-4.83 ; p<0.001\right)$. Ten minutes later, the reflex recovered from inhibition $(\bar{x}=$ $99.8 \pm 10.2 \%$ ). Control preparations, which received bath application of saline solution (see Materials and Methods), showed stable reflex responding throughout the experiment (test $1, \bar{x}=$ $96.3 \pm 5.97 \%$; test $2, \bar{x}=97.2 \pm 5.19 \%$ ). Moreover, a betweengroup comparison showed that the experimental group exhibited a significantly reduced reflex response in test 1 compared to the control group $\left(t_{18}=2.27 ; p<0.04\right)$. Thus, consistent with our previous cellular observations, 5 -HT produces significant inhibition of the behavioral reflex response.

\section{Discussion}

\section{5-HT as a facilitatory modulator in Aplysia}

5-HT produces presynaptic facilitation in siphon sensory neurons in Aplysia, and the mechanism of this facilitatory process is understood in considerable detail. Briefly, 5-HT, acting via a $\mathrm{G}$-protein, is known to stimulate adenylate cyclase and thereby produce an elevation of intracellular CAMP in the sensory neuron. The increase in cAMP in turn activates a cAMP-dependent protein kinase, which mediates phosphorylation of one or more substrates that leads to closure of a specific potassium channel (the S-channel, which may itself be the target phosphoprotein), resulting in increased excitability of the sensory neuron, actionpotential broadening, and greater transmitter release (Bernier et al., 1982; Castellucci et al., 1982; Siegelbaum et al., 1982; for reviews, see Kandel and Schwartz, 1982; Byrne, 1987; Carew, 1987; Hawkins et al., 1987). In addition to this mechanism, 5-HT has also been shown to enhance synaptic release by a "second process," which is less dependent on action-potential duration (Hochner et al., 1986; Gingrich et al., 1988), and to modify potassium conductances other than the S-channel (Baxter and Byrne, 1989; Walsh and Byrne, 1989).

That 5-HT plays a role in reflex facilitation during learning (e.g., sensitization and dishabituation) has been supported by findings at both cellular and behavioral levels. For example, 5-HT mimics head or tail shock-induced synaptic enhancement in the siphon withdrawal circuit (Brunelli et al., 1976) and can produce facilitation of the gill withdrawal reflex in a reduced preparation (Abrams et al., 1984). Additionally, identified serotonergic interneurons in the cerebral ganglion (the $\mathrm{CB} 1$ cells) produce presynaptic facilitation of sensory neurons in the siphon withdrawal circuit and are activated by tail shock. These interneurons thus constitute a serotonergic pathway that might mediate tail shock-induced reflex modulation (Mackey et al., 1989). A behavioral test of the necessity of 5-HT for reflex facilitation has been carried out using 5,7-dihydroxytryptamine to deplete 5-HT in the intact animal. 5-HT-depleted animals exhibit siphon withdrawal reflex responding, but do not show dishabitua-

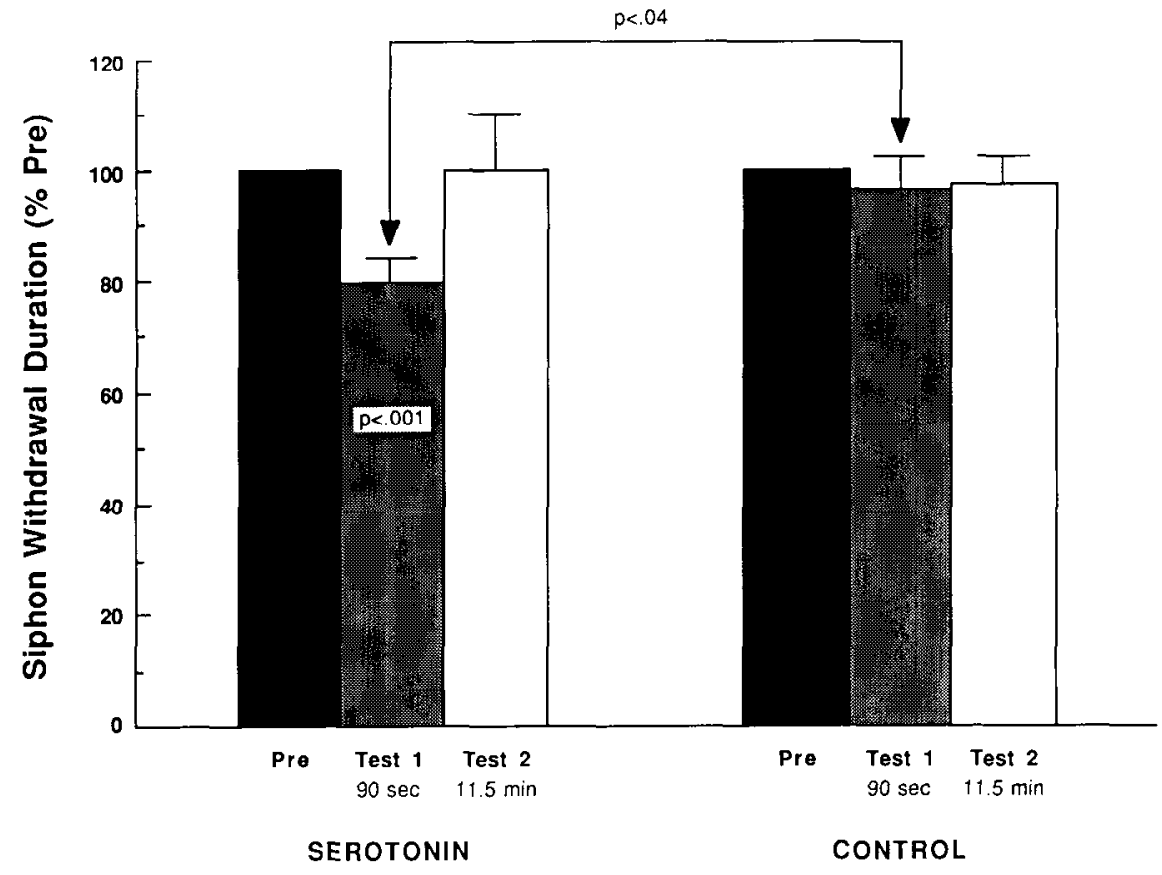

Figure 8 . Effects of 5-HT on the siphon withdrawal reflex in a reduced preparation. Siphon withdrawal duration is expressed as a percentage of the mean pretest response, which is indicated by the solid bars at $100 \%$. Error bars indicate SEM. In the first test after $50 \mu \mathrm{M}$ 5-HT application (shaded bars), siphon withdrawal duration of preparations that received 5 -HT $(N=10)$ is significantly inhibited below baseline. Controls $(N=10)$ show no inhibition. Moreover, a between-group comparison showed that siphon withdrawal in experimental preparations is significantly inhibited compared to control preparations. At test 2 (10 min later; open bars), siphon withdrawal has returned to pretest levels. 
Figure 9. Comparison of the inhibitory effects of tail shock and 5-HT. Data are shown for both siphon withdrawal duration (open circles) and complex EPSP amplitude (solid squares). All responses are expressed as a percentage of pretest baseline, which is indicated by the broken line at $100 \%$. $A$, In the intact, frecly moving animal, tail shock produces transient reflex inhibition (test $1,90 \mathrm{sec}$ after shock). Sensitization is apparent only after a delay of more than 20 min (tests 2 and 3). Data are replotted from Marcus et al. (1988). B, In a reduced preparation (siphon, gill, mantle shelf, and tail, attached to the CNS via peripheral nerves), tail shock produces comparable inhibition of both the withdrawal reflex and complex EPSP. Data are replotted from Wright et al. $(1988,1989)$. C. In a reduced preparation (siphon, gill, and mantle shelf, attached to abdominal ganglion via the siphon nerve), the effects of 5-HT on the reflex and the complex EPSP parallel the inhibition observed in intact animals $(A)$ and reduced preparations $(B)$ after tail shock.

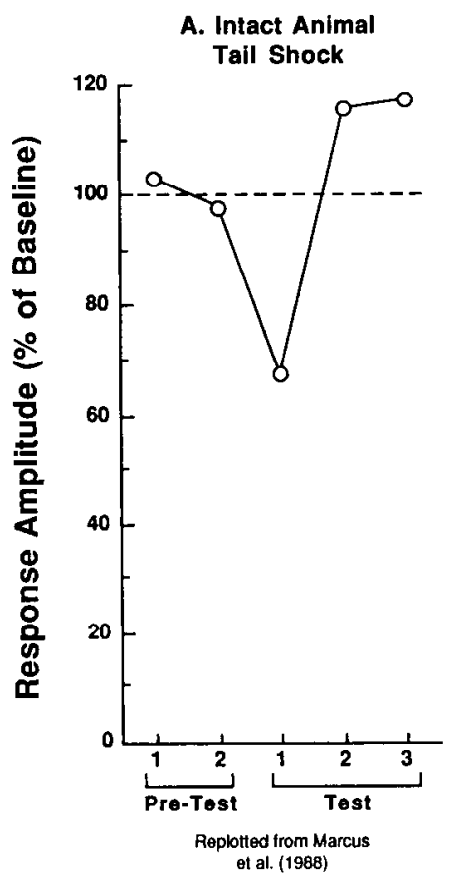

B. Reduced Preparation

C. Reduced Preparation Tail Shock Serotonin

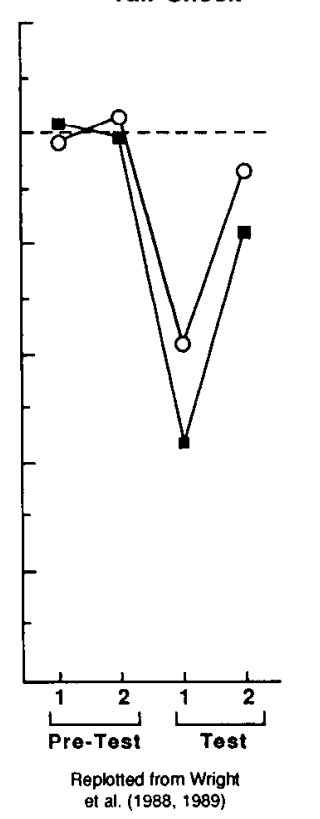

tion in response to tail shock (Glanzman et al., 1989). Thus, taken collectively, there is considerable evidence implicating 5-HT as playing an important role in reflex facilitation in Aplysia.

\section{Possible inhibitory role of 5-HT}

It has long been known that molluscan neurons exhibit multiple responses to exogenously applied 5-HT (Gerschenfeld and Paupardin-Tritsch, 1974a,b; for review, see Gerschenfeld, 1973). Consistent with this diversity of responses, 5-HT has recently been found to have inhibitory as well as facilitatory effects in Aplysia. For example, in addition to broadening of the action potential and synaptic enhancement in one subpopulation of sensory neurons in the cerebral ganglion, 5-H I also produces action-potential narrowing and synaptic inhibition in another subclass of sensory cells (Rosen et al., 1989). Morcover, in the present article we have shown that both facilitatory and inhibitory actions of 5-HT can be observed in the neural circuit for siphon withdrawal. Specifically, 5-HT produces enhancement of monosynaptic EPSPs from siphon sensory neurons and, simultaneously, inhibition of complex EPSPs in siphon motor neurons. Additionally, we have found that 5-HT inhibits the nondecremented siphon withdrawal reflex in a reduced behavioral preparation. A related behavioral observation has been reported by Rubin (1981), who found that superfusion of the abdominal ganglion with $5-\mathrm{HT}(1-100 \mu \mathrm{M})$ did not facilitate the amplitude of the gill withdrawal reflex; rather, in some instances, 5-HT appeared to produce a slight diminution in reflex amplitude.

The inhibitory effect of 5-HT on siphon withdrawal that we observe contrasts with the results of Abrams et al. (1984), who report that 5-HT can producc reflex facilitation in Aplysia. There are several differences between the experiments of Abrams et al. (1984) and the present experiments that may contribute to the different effects observed for 5-HT. For example, Abrams et al. (1984) measured gill withdrawal responses elicited by elec- tric shock of the siphon skin; moreover, based on the short (30sec) interstimulus interval that they used, it is likely that they were examining decremented responses. In the present study, we measured siphon withdrawal responses elicited by water jet stimuli to the siphon (comparable to the studies of Marcus et al., 1988; Wright et al., 1989, 1991; Wright and Carew, 1990); moreover, we examined nondecremented reflex responses. Thus, the study by Abrams et al. (1984) and the present experiments differed in the stimuli used to activate the reflex, the initial state of the reflex, and the response measured. The difference in the response that was measured is especially interesting in light of the recent report by Hawkins et al. (1990) that the gill withdrawal and siphon withdrawal components of the overall defensive reflex can be differentially modulated by tail shock. It will now be very interesting to examine systematically the effects of 5-HT on reflex responding under these different experimental conditions. Such a comparison could provide important insights into the mechanisms by which 5-HT can produce reflex facilitation in some behavioral contexts and reflex inhibition in others.

The transient inhibition produced by 5 -HT of both the complex EPSP and the behavioral reflex in the present study parallels the inhibition observed in the intact animal and in central neural circuits following tail shock (Marcus et al., 1988; Wright et al., 1989, 1991; Wright and Carew, 1990). The parallel magnitude and time course of inhibition observed at these different levels of analysis are illustrated in Figure 9. These observations suggest the hypothesis that inhibitory modulation of elements in the siphon withdrawal circuit, mediated at least in part by 5-HT, might be involved in the behavioral inhibition that is induced by tail shock.

Several possible mechanisms may contribute to the inhibitory effect of 5-HT that we observe in our behavioral and cellular experiments. For purposes of comparison, these putative mechanisms may be considered as modulation at three possible sites: (1) presynaptic, (2) postsynaptic, or (3) interneuronal. We will discuss each of these possibilities in turn. 
Presynaptic changes in the LE siphon sensory neurons have been shown to underlie the synaptic enhancement produced by 5-HT. It is possible that the inhibitory effect of 5-HT might be mediated by direct presynaptic inhibition of a separate population of sensory neurons, analogous to the differential effects of 5-HT on discrete subclasses of sensory neurons in the cerebral ganglion (Rosen et al., 1989). Thus far, the siphon sensory neurons that have been characterized appear to have only a facilitatory response to 5-HT. However, Dubuc and Castellucci (1991) have recently identified several new populations of sensory neurons in the abdominal ganglion of Aplysia. This leaves open the possibility that a novel class of siphon sensory neurons may be inhibited by 5 -HT and thus could contribute to the behavioral and cellular effects we observe.

A second possibility is that 5-HT might act by causing postsynaptic inhibition at the siphon motor neurons. Frost et al. (1988) directly examined the effects of 5-HT on siphon motor neurons and found only facilitatory effects. Consistent with these observations, we have not observed any indication of postsynaptic inhibitory effects of 5-HT. For example, 5-HT does not produce hyperpolarization of the motor neuron's membrane potential. While it is possible that 5 -HT might produce inhibition by shunting the input resistance of motor neurons, our observation that different input pathways (from monosynaptic and polysynaptic sources) that converge on the same postsynaptic motor neuron are differentially modulated by 5-HT suggests that the effects we observed are at least in part due to changes in elements presynaptic to the motor neurons. Thus, though possible, it is unlikely that postsynaptic changes in the motor neuron account substantially for the inhibitory effects of 5-HT that we observed.

A third alternative, which we are currently investigating, is that the inhibition observed in response to 5-HT could reflect modulation of interneurons in the siphon withdrawal circuit. A number of interneurons have been described that participate in mediation or modulation of the siphon withdrawal reflex (Hawkins et al., 1981a,b; Frost et al., 1988; Wright and Carew, 1990; Wright et al., 1991). Modulation of one or more interneurons by 5 -HT could produce reflex inhibition that, at a cellular level, could be reflected in differential modulation of the complex EPSP and the monosynaptic EPSP. For example, 5-HT could increase synaptic transmission from the LE sensory neurons onto inhibitory interneurons, which in turn could inhibit the motor cells sufficiently to account for the behavioral and cellular inhibition we observed. To examine this and related hypotheses, we have begun to examine inhibitory interneurons in the siphon withdrawal circuit to determine whether they may be activated or facilitated by 5-HT and thus contribute to reflex inhibition.

In conclusion, previous behavioral and cellular experiments indicate that tail shock can have diverse modulatory effects in the siphon withdrawal reflex in Aplysia (Krontiris-Litowitz et al., 1987; Mackey et al., 1987; Marcus et al., 1987, 1988; Wright et al., 1988, 1989, 1991; Wright and Carew, 1990). Taken in conjunction with these previous findings, our results suggest that, in addition to its well-established facilitatory role in reflex modulation in Aplysia, 5-HT might play an important role in inhibitory modulation, as well. Such a possibility is consistent with the observed effects of 5-HT in other neural systems. For example, in the mammalian brain, 5-HT has been shown to produce both inhibition (e.g., in dorsal raphe and hippocampal pyramidal neurons; Aghajanian et al., 1972; Segal, 1980) and facilitation (e.g., in facial motor nucleus; McCall and Aghaja- nian, 1979). These opposing effects of 5-HT are mediated by pharmacologically distinct 5-HT receptors (for review, see Aghajanian et al., 1990). Multiple receptor types for 5-HT have also been identified in a number of invertebrate systems (for review, see Walker, 1985), raising the possibility that the opposing modulatory effects observed in the siphon withdrawal reflex of Aplysia may reflect the action of 5-HT on different receptor subtypes. Recent observations by Mercer and Carew (1991) lend support to the possibility of different 5-HT receptor types in Aplysia. They found that some 5-HT blockers can selectively antagonize certain facilitatory effects of 5-HT in $A p l y$ sia sensory neurons (e.g., spike broadening) while leaving other facilitatory effects (e.g., increased excitability) intact. Thus $A p l y$ sia may provide a useful preparation in which to explore the diverse behavioral and cellular actions of 5-HT at a mechanistic level.

\section{References}

Abrams TW, Castellucci VF, Camardo JS, Kandel ER, Lloyd PE (1984) Two endogenous neuropeptides modulate the gill and siphon withdrawal reflex in Aplysia by presynaptic facilitation involving cAMPdependent closure of a serotonin-sensitive potassium channel. Proc Natl Acad Sci USA 81:7956-7960.

Aghajanian GK, Haigler HJ, Bloom FE (1972) Lysergic acid diethylamide and serotonin: direct actions on serotonin-containing neurons in rat brain. Life Sci 11:615-622.

Aghajanian GK, Sprouse JS, Sheldon P, Rasmusson K (1990) Electrophysiology of the central serotonin system: receptor subtypes and transducer mechanisms. Ann NY Acad Sci 600:93-103.

Baxter DA, Byrne JH (1989) Serotonergic modulation of two potassium currents in the pleural sensory neurons of Aplysia. J Neurophysiol 62:665-679.

Bernier L, Castellucci VF, Kandel ER, Schwartz JH (1982) Facilitatory transmitter causes a selective and prolonged increase in adenosine $3^{\prime}$ : $5^{\prime}$-monophosphate in sensory neurons mediating the gill and siphon withdrawal reflex in Aplysia. J Neurosci 2:1682-1691.

Brunelli M, Castellucci V, Kandel ER (1976) Synaptic facilitation and behavioral sensitization in Aplysia: possible role of serotonin and cyclic AMP. Science 194:1178-1180.

Byrne JH (1987) Cellular analysis of associative learning. Physiol Rev $67: 329-439$.

Byrne JH, Castellucci VF, Kandel ER (1978) Contribution of individual mechanoreceptor sensory neurons to defensive gill-withdrawal reflex in Aplysia. J Neurophysiol 41:418-431.

Carew TJ (1987) Cellular and molecular advances in the study of learning in Aplysia. In: Neural and molecular bases of learning (Changeaux JP, Konishi M, eds), pp 177-204. New York: Wiley.

Carew TJ, Sahley CL (1986) Invertebrate learning and memory: from behavior to molecules. Annu Rev Neurosci 9:435-487.

Carew TJ, Walters ET, Kandel ER (1981) Classical conditioning in a simple withdrawal reflex in Aplysia californica. J Ncurosci 1:14261437.

Castellucci VF, Nairn A, Greengard P, Schwartz JH, Kandel ER (1982) Inhibitor of adenosine $3^{\prime}: 5^{\prime}$-monophosphate-dependent protein kinase blocks presynaptic facilitation in Aplysia. J Neurosci 2:16731681 .

Dubuc B, Castellucci VF (1991) Receptive fields and properties of a new cluster of mechanoreceptor neurons innervating the mantle region and branchial cavity of the marine mollusc Aplysia californica. J Exp Biol 156:315-334.

Fitzgerald K, Carew TJ (1989) Serotonin differentially modulates monosynaptic and complex EPSPs in siphon motor neurons in $A p l y$ sia. Soc Neurosci Abstr 15:1265.

Fitzgerald K, Wright WG, Marcus EA, Carew TJ (1990) Multiple forms of non-associative plasticity in Aplysia: a behavioural, cellular and pharmacological analysis. Philos Trans R Soc Lond [Biol] 329: 171-178.

Frost WN, Clark GA, Kandel ER (1988) Parallel processing of shortterm memory for sensitization in Aplysia. J Neurobiol 19:297-334.

Gerschenfeld HM (1973) Chemical transmission in invertebrate cen- 
tral nervous systems and neuromuscular junctions. Physiol Rev 53: $1-119$.

Gerschenfeld HM, Paupardin-Tritsch D (1974a) Ionic mechanisms and receptor properties underlying the responses of molluscan neurones to 5-hydroxytryptamine. J Physiol (Lond) 243:427-456.

Gerschenfeld HM, Paupardin-Tritsch D (1974b) On the transmitter function of 5-hydroxytryptamine at excitatory and inhibitory monosynaptic junctions. J Physiol (Lond) 243:457-481.

Gingrich KJ, Baxter DA, Byrne JH (1988) Mathematical model of cellular mechanisms contributing to presynaptic facilitation. Brain Res Bull 21:513-520.

Glanzman DL, Mackey SL, Hawkins RD, Dyke AM, Lloyd PE, Kandel ER (1989) Depletion of serotonin in the nervous system of Aplysia reduces the behavioral enhancement of gill withdrawal as well as the heterosynaptic facilitation produced by tail shock. J Neurosci 9:42004213.

Hawkins RD, Castellucci VF, Kandel ER (1981a) Interneurons involved in mediation and modulation of gill-withdrawal reflex in Aplysia. I. Identification and characterization. J Neurophysiol 45:304 314.

Hawkins RD, Castellucci VF, Kandel ER (1981b) Interneurons involved in mediation and modulation of gill-withdrawal reflex in $A p l y-$ sia. II. Identified neurons produce heterosynaptic facilitation contributing to behavioral sensitization. J Neurophysiol 45:315-326.

Hawkins RD, Clark GA, Kandel ER (1987) Cell biological studies of learning in simple vertebrate and invertebrate systems. In: Handbook of physiology, Sec I, Higher functions of the nervous system, Vol 6 (Plum F, ed), pp 25-83. Bethesda, MD: American Physiological Society.

Hawkins RD, Cohen TE, Henzi VA, Kandel ER (1990) Parallel dishabituation and sensitization with no inhibition of gill-withdrawal reflex in Aplysia. Soc Neurosci Abstr 16:19.

Hochner B, Klein M, Schacher S, Kandel ER (1986) Additional component in the cellular mechanism of presynaptic facilitation contributes to behavioral dishabituation in Aplysia. Proc Natl Acad Sci USA 83:8794-8798.

Kandel ER, Schwartz JH (1982) Molecular biology of learning: modulation of transmitter release. Science 218:433-443.

Krontiris-Litowitz JK, Erickson MT, Walters ET (1987) Central suppression of defensive reflexes in Aplysia by noxious stimulation and by factors released from body wall. Soc Neurosci Abstr 13:815.

Mackey SL, Glanzman DL, Small SA, Dyke AM, Kandel ER, Hawkins RD (1987) Tail shock produces inhibition as well as sensitization of the siphon-withdrawal reflex of Aplysia: possible behavioral role for presynaptic inhibition mediated by the peptide Phe-Met-Arg-Phe$\mathrm{NH}_{2}$. Proc Natl Acad Sci USA 84:8730-8734.
Mackey SL, Kandel ER, Hawkins RD (1989) Identified serotonergic neurons LCB1 and RCB1 in the cerebral ganglia of Aplysia produce presynaptic facilitation of siphon sensory neurons. J Neurosci 9:42274235.

Marcus EA, Nolen TG, Rankin CH, Carew TJ (1987) Behavioral dissociation of dishabituation, sensitization and inhibition in the siphon withdrawal reflex of adult Aplysia. Soc Neurosci Abstr 13:816.

Marcus EA, Nolen TG, Rankin CH, Carew TJ (1988) Behavioral dissociation of dishabituation, sensitization, and inhibition in Aplysia. Science 241:210-213.

McCall RB, Aghajanian GK (1979) Serotonergic facilitation of facial motoneuron excitation. Brain Res 169:11-27.

Mercer AR, Carew TJ (1991) Cyproheptadine blocks 5-HT-induced spike broadening but not 5-HT-induced anti-accommodation: evidence for multiple 5-HT receptors in Aplysia sensory neurons. Soc Neurosci Abstr, in press.

Rosen SC, Susswein AJ, Cropper EC, Weiss KR, Kupferman I (1989) Selective modulation of spike duration by serotonin and the neuropeptides, FMRFamide, $\mathrm{SCP}_{\mathrm{B}}$, buccalin and myomodulin in different classes of mechanoafferent neurons in the cerebral ganglion of Aplysia. J Neurosci 9:390-402.

Rubin P (1981) Dopamine mimicry of aroused gill reflex behaviors in Aplysia californica. PhD thesis, University of Calgary.

Segal M (1980) The action of serotonin in the rat hippocampal slice preparation. J Physiol (Lond) 303:423-439.

Siegelbaum SA, Camardo JS, Kandel ER (1982) Serotonin and cyclic AMP close single $\mathrm{K}^{+}$channels of Aplysia sensory neurons in cell-free membrane patches. Nature 299:413-417.

Walker RJ (1985) The pharmacology of serotonin receptors in invertebrates. In: Neuropharmacology of serotonin (Green AR, ed), pp 366-407. New York: Oxford UP.

Walsh JP, Byrne JH (1989) Modulation of a steady-state $\mathrm{Ca}^{2+}$-activated, $\mathrm{K}^{+}$current in tail sensory neurons of Aplysia: role of serotonin and cAMP. J Neurophysiol 61:32-44.

Wright WG, Carew TJ (1990) Contribution of interneurons to tailshock induced inhibition of the siphon withdrawal reflex in Aplysia. Soc Neurosci Abstr 16:20.

Wright WG, Marcus EA, Thaker H, Carew TJ (1988) A cellular analysis of tail-shock induced inhibition in the siphon withdrawal reflex of Aplysia. Soc Neurosci Abstr 14:841.

Wright WG, Marcus EA, Carew TJ (1989) Dissociation of monosynaptic and polysynaptic contributions to dishabituation, sensitization and inhibition in Aplysia. Soc Neurosci Abstr 15:1265.

Wright WG, Marcus EA, Carew TJ (1991) A cellular analysis of inhibition in the siphon withdrawal reflex of Aplysia. J Neurosci 11: 2498-2509. 